\title{
The Blood Pressure "Uncertainty Range" - a pragmatic approach to overcome current diagnostic uncertainties (II) Cornel Pater*
}

\author{
Address: Chippenham, UK \\ Email: Cornel Pater* - drcornelpater@aol.com \\ * Corresponding author
}

Published: 06 April 2005

Current Controlled Trials in Cardiovascular Medicine 2005, 6:5 doi:10.1 186/1468-6708-6-5

This article is available from: http://crm.controlled-trials.com/content/6/1/5

(c) 2005 Pater; licensee BioMed Central Ltd.

This is an Open Access article distributed under the terms of the Creative Commons Attribution License (http://creativecommons.org/licenses/by/2.0), which permits unrestricted use, distribution, and reproduction in any medium, provided the original work is properly cited.
Received: 04 March 2005

Accepted: 06 April 2005

\begin{abstract}
A tremendous amount of scientific evidence regarding the physiology and physiopathology of high blood pressure combined with a sophisticated therapeutic arsenal is at the disposal of the medical community to counteract the overall public health burden of hypertension. Ample evidence has also been gathered from a multitude of large-scale randomized trials indicating the beneficial effects of current treatment strategies in terms of reduced hypertension-related morbidity and mortality.

In spite of these impressive advances and, deeply disappointingly from a public health perspective, the real picture of hypertension management is overshadowed by widespread diagnostic inaccuracies (underdiagnosis, overdiagnosis) as well as by treatment failures generated by undertreatment, overtreatment, and misuse of medications.

The scientific, medical and patient communities as well as decision-makers worldwide are striving for greatest possible health gains from available resources.

A seemingly well-crystallised reasoning is that comprehensive strategic approaches must not only target hypertension as a pathological entity, but rather, take into account the wider environment in which hypertension is a major risk factor for cardiovascular disease carrying a great deal of our inheritance, and its interplay in the constellation of other, well-known, modifiable risk factors, i.e., attention is to be switched from one's "blood pressure level" to one's absolute cardiovascular risk and its determinants. Likewise, a risk/benefit assessment in each individual case is required in order to achieve best possible results.

Nevertheless, it is of paramount importance to insure generalizability of ABPM use in clinical practice with the aim of improving the accuracy of a first diagnosis for both individual treatment and clinical research purposes. Widespread adoption of the method requires quick adjustment of current guidelines, development of appropriate technology infrastructure and training of staff (i.e., education, decision support, and information systems for practitioners and patients). Progress can be achieved in a few years, or in the next 25 years.
\end{abstract}

\section{Introduction}

During the past decades, hypertension, denoting abnormal

elevation of blood pressure, has commonly been assigned a distinct disease quality. The majority of the medical community as well as renowned medical textbooks have 
considered it a pathological entity requiring diagnostic and appropriate treatment in most individuals having it.

Inherent in the 100-year old approach of discriminating between normal and abnormal blood pressure is, however, an arbitrary threshold established currently at 140/ $90 \mathrm{mmHg}$ for mild hypertension and two higher cut-off values to define moderate and severe hypertension. This classification, still maintained as such by the ESH [1] and WHO [2] guidelines, has been in use for many decades both for management of hypertension in individual subjects and for defining patient population samples targeted for testing of new antihypertensive drugs.

It is common knowledge, however, that up to $95 \%$ of hypertensive individuals have high blood pressure of unknown etiology denoted essential hypertension. The majority of these have mild hypertension while some $10 \%$ of them have either moderate or severe degrees of hypertension.

Classically, the diagnosis of essential hypertension has been regarded as pretty straightforward, as long as a secondary hypertension could be ruled out with confidence.

While this latter entity can, on justifiable grounds, be considered a disease, essential hypertension is a quantitative expression of the fluctuations of a biologic variable - the blood pressure - that should be considered a major risk factor for cardiovascular disease at best, rather than a disease by itself.

Nevertheless, with increasing awareness that the trade-off between normality and abnormality on a blood pressure curve is confounded by large diurnal and random variation of the blood pressure variable, by individual factors such as age, sex, race as well as by a great number of potential errors occurring during blood pressure measurement per se, the medical and scientific community are desperately in search for approaches to increase the accuracy of diagnosis and management of hypertension and to shift the weight of decision making from the current "BPvalue"-focused attitude to the appraisal of any patient's absolute risk, rather than his/her individual risks (i.e., high blood pressure, hypercholesterolemia, smoking, overweight, etc.) [3-5].

The driver behind the need for radical change is at least two fold:

1. The widespread awareness that the hypertensionrelated risk - in terms of cardiovascular complications, stroke and renal disease - rises in relation to increases of both systolic and diastolic blood pressure [6-13].
2. The hypertension diagnosis currently implies not only exclusion of secondary causes of hypertension but as well, careful consideration is to be given to differentiating entities like: white coat hypertension [14-17], white coat effect $[18,19]$, masked hypertension [20-22] and prehypertension, from the genuine, sustained hypertension [23].

The clustering of these entities around the current diagnostic cut-off point $(140 / 90 \mathrm{mmHg})$ generates a BP uncertainty range $(130 / 85-160 / 95 \mathrm{mmHg})$ reflecting a universally widespread inaccuracy of a first diagnosis based on office BP measurements and a consequent inappropriate long-term management of the subjects assessed.

\section{Blood pressure measurement as a diagnostic test - a clinical epidemiology perspective}

Commonly, variation in clinical medicine may be due to fluctuations of biologic variables or the presence or absence of disease as well as the nature of that disease and its severity; it may also be due to differences in measurement technique, errors in measurement, observer bias, and to a great extent to random variation.

The blood pressure variable happens to be a typical example that displays all the aforementioned variation parameters. An attempt to understand this variation through gaining insight in relative simple epidemiology and statistical concepts and then acting on the basis of the new acquired knowledge, might be the key to account for the blood pressure overall variability, to accurately interpret the prognostic significance of any blood pressure values and confidently manage pharmacological therapy in all hypertensive patients.

In the general population blood pressure values follow a smooth bell-shaped distribution as displayed in Fig. 1 for the SBP and in Fig. 2 for the DBP. The two histograms attempt to account for the known general prevalence of hypertension worldwide [24], with higher figures for the SBP as compared with DBP due to their divergent pattern at higher ages (and both sexes) [25]. The black bars highlight the frequency distribution of the blood pressure values considered abnormal (according to the arbitrary threshold of 140/90 $\mathrm{mmHg}$ ).

The distribution of SBP is slightly skewed to the right due to the high proportion of people with $\mathrm{BP}$ values in the range $140-160 \mathrm{mmHg}$ [26].

Certainly, both systolic and diastolic blood pressure belong to one and the same, simplified, theoretical normal distribution (Fig. 3) assumed to describe the underlying population from which relevant data might be derived $[27,28]$. Fig. 3 suggests that all normal blood pressure 


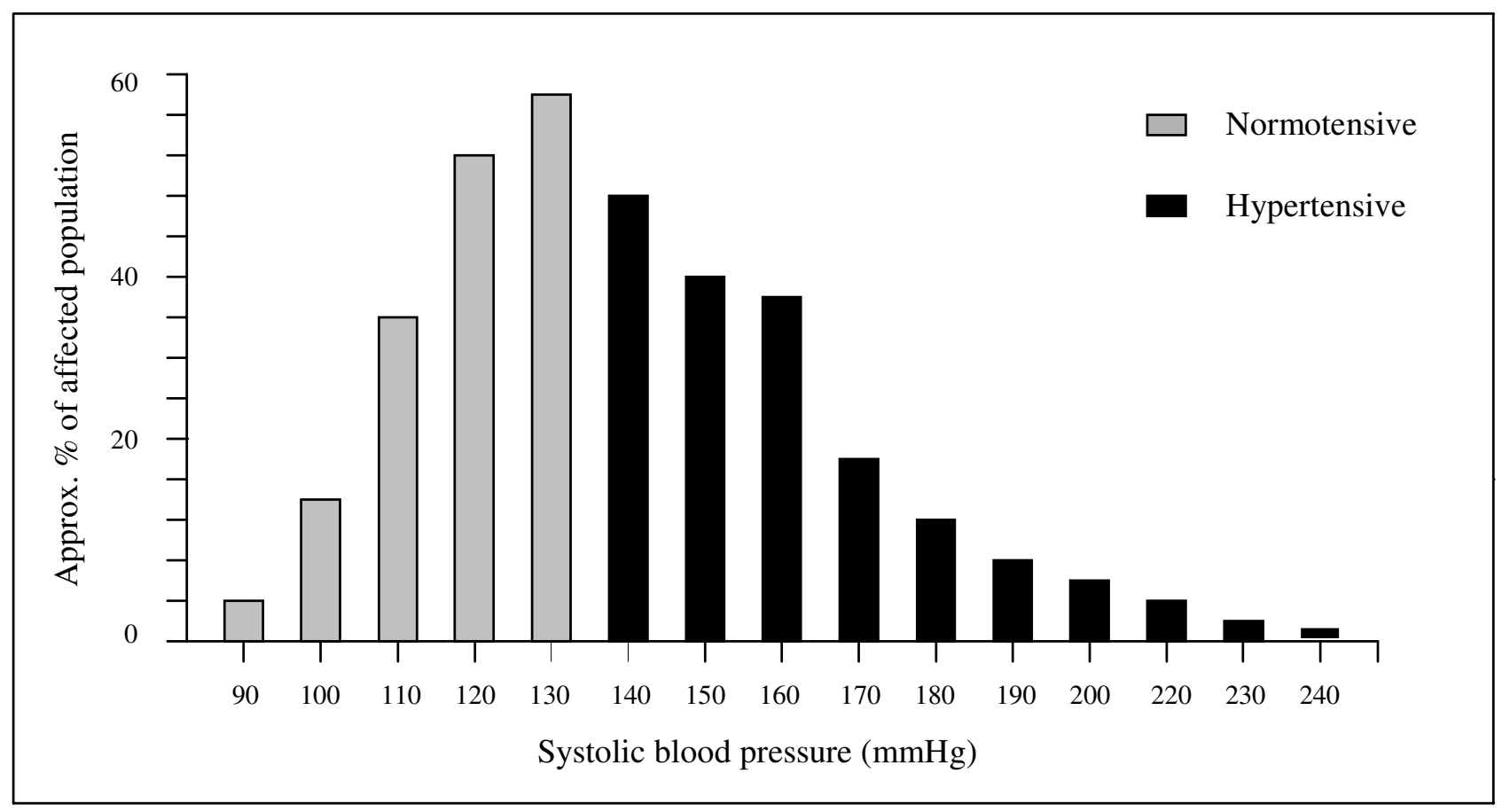

Figure I

Normal distribution of SBP values in the general population.

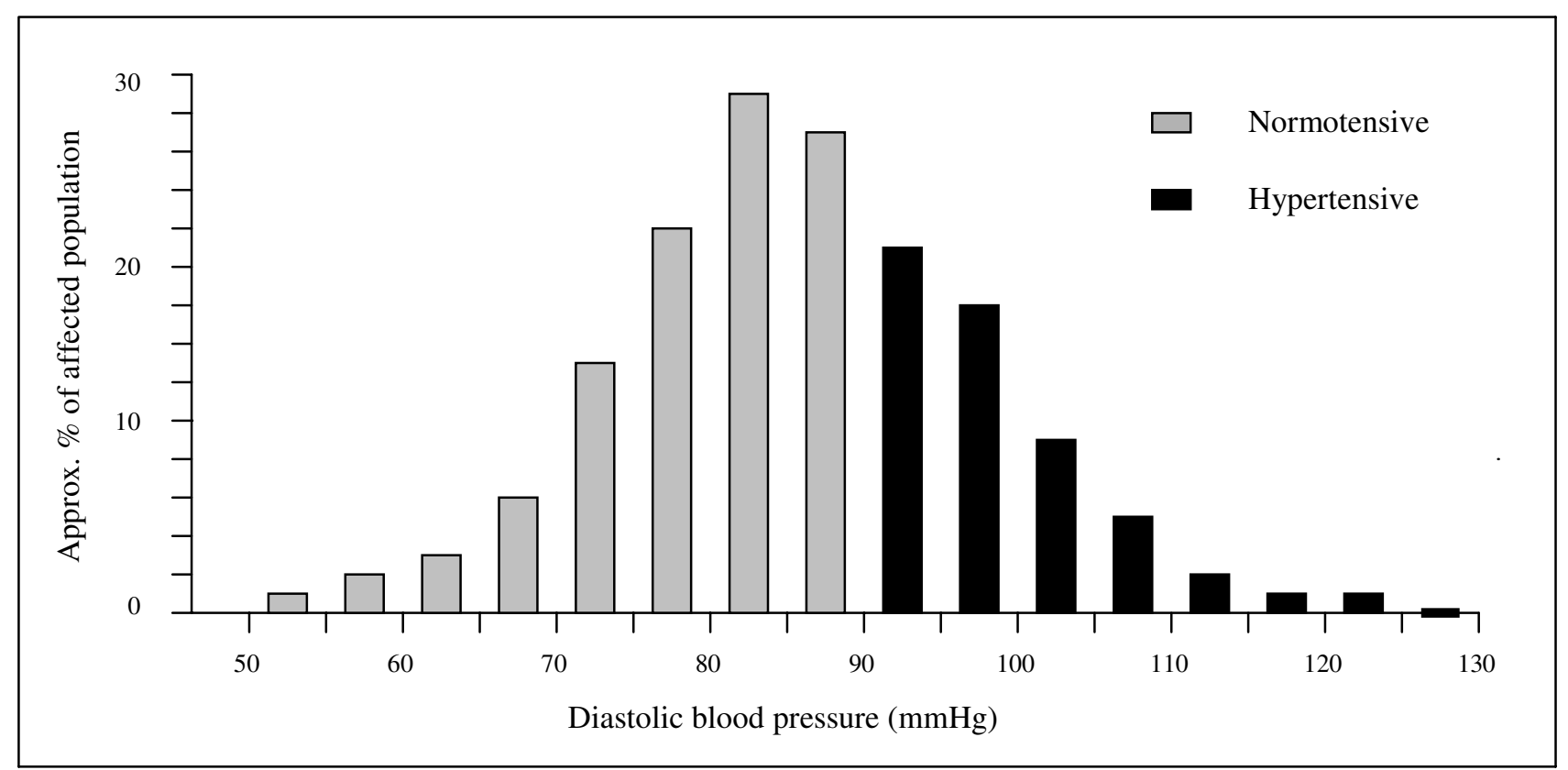

Figure 2

Normal distribution of DBP values in the general population. 


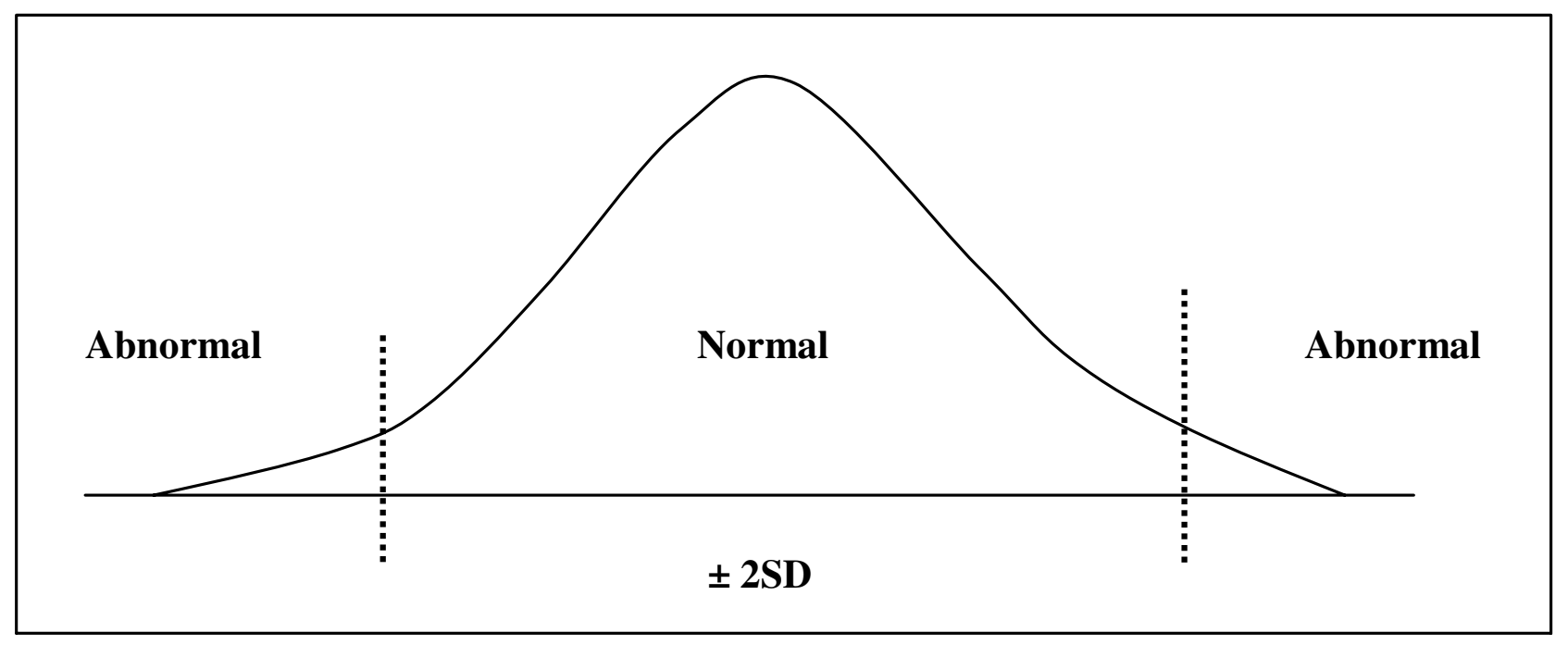

Figure 3

Illustration of the normality concept in a normal distribution.

values measured in the population are comprised by the interval given by the mean \pm two standard deviations ( $M$ $\pm 2 \mathrm{SD})$.

Assuming that the commonly used office blood pressure measurement was an ideal test (a "gold standard", which is not the case), it could separate all healthy people from those who have the disease (i.e., people with BP values that require treatment from those who do not). In such a hypothetical case the blood pressure measurement would be $100 \%$ sensitive and $100 \%$ specific, with no false-positive or false-negative results.

In reality, things are much different; there are two normal distributions of blood pressure "test" results. One is for individuals free of disease and one for individuals who have the disease. Framing the reality in this way is still misleading because in practice many patients may have raised blood pressure levels (but are "disease free", insofar as they may not need pharmacologic treatment - e.g., white coat hypertension) [29,30] and, many patients may display apparently normal blood pressure values but, definitely need pharmacologic treatment (because of high absolute risk for CVD, the presence of a compelling indication or of masked hypertension) [29,30].

In fact, there is an overlap of the two distributions and that overlap is rather large; it predisposes to both overand underdiagnosis, i.e., false-positive and false-negative results. The immediate consequence under the current cir- cumstances of conventional office BP measurement is that setting any test value (i.e., BP threshold) as cut-off point to distinguish between "normal" and "abnormal", will misclassify a great proportion of the patients falling into the overlap area (Fig. 4) - a real uncertainty range exposing to misdiagnosis (i.e., under- and overdiagnosis) [30].

As Fig. 4 illustrates, for our diagnostic "test" (the office BP measurement) which does not behave as a "gold standard", there are four distinct alternatives [31]:

1. True negatives (TN) - subjects without the disease who test negative (i.e., normal BP and no indication for blood pressure lowering treatment).

2. True positives (TP) - subjects who have the disease and test positive (i.e., sustained hypertension requiring pharmacologic treatment).

3. False-negatives (FN) - subjects who have the disease but test negative (i.e., normal BP, however, in need to get pharmacologic treatment (e.g., masked hypertension).

4. False-positives (FP) - subjects who do not have the disease but test positive (i.e., subjects with high blood pressure values but in no need for pharmacologic treatment (e.g., white coat hypertension).

Fig. 4 also illustrates the dynamic complexity of what goes on around the cut-off point selected. As mentioned in the 


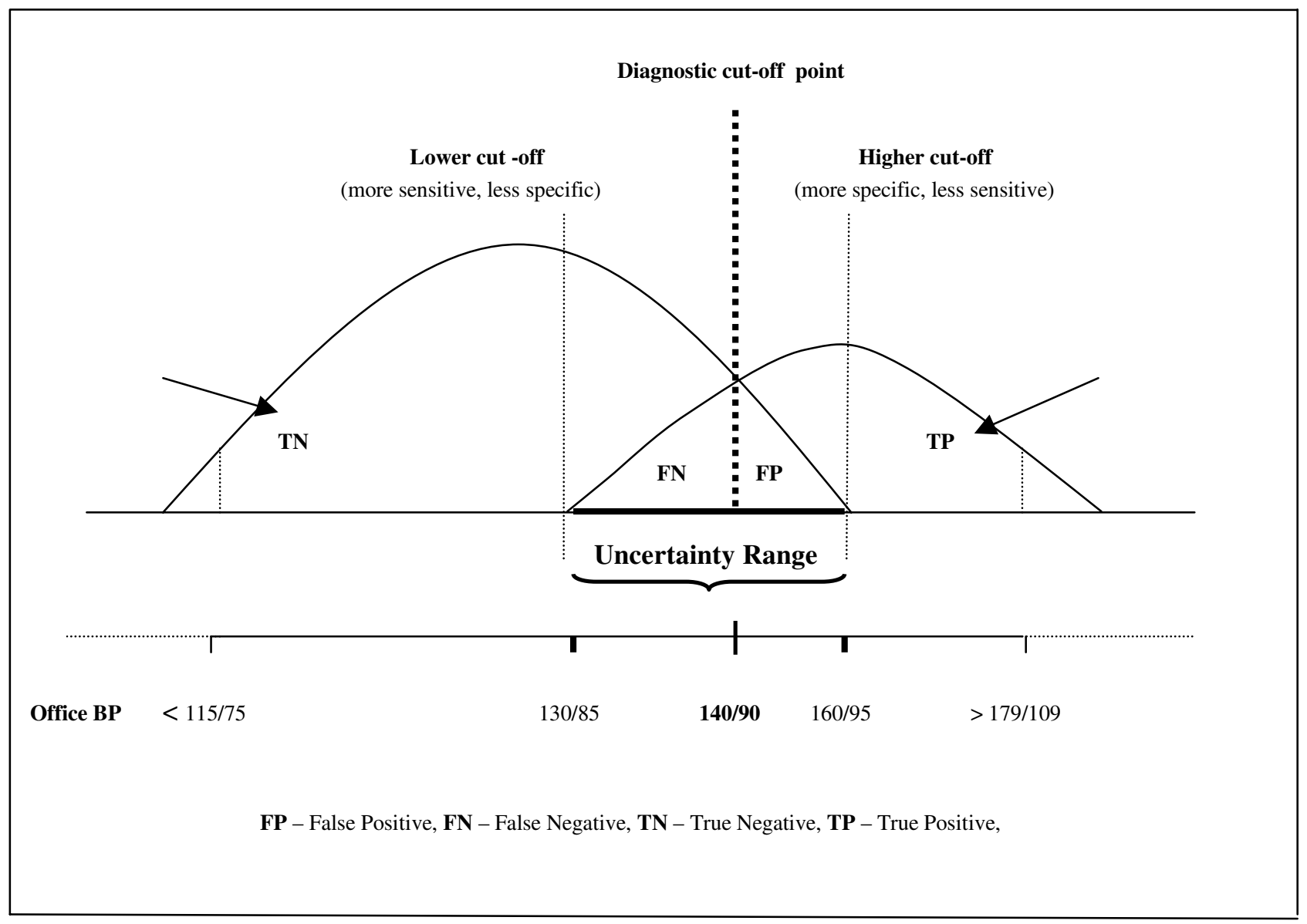

Figure 4

Result alternatives by office BP measurement and the trade-off displayed by the sensitivity and specificity of the method as related to the cut-off point selected (140/90 $\mathrm{mmHg}$ ).

first part of this paper, many national hypertension societies still maintain a cut-off point for blood pressure normality/abnormality by $160 / 95 \mathrm{mmHg}$ [32]. For those societies which decided to select $140 / 90 \mathrm{mmHg}$ as cut-off point, the switch from $160 / 95$ to $140 / 90 \mathrm{mmHg}$ has meant a substantial change of several important diagnostic parameters (including the prevalence of the condition) [33].

Namely, the sensitivity of the test has increased, however, with a simultaneous decrease in its specificity. The number of TPs has increased as compared to the number of FNs. Further, the move of the cut-off point to the left on the BP curve has caused an increase in FPs as compared to the FNs.
With other words, a high cut-of point on the BP curve implies less false-positive results (and less overdiagnosis) with the reverse occurring if the cut-off point is low.

Selection of "best cut-off point" can be enhanced by constructing a receiver operating characteristic (ROC) curve (Fig. 5) [34]. Such a curve displays sensitivity on the X-axis and the false positive error rate (1-specificity) on the Y-axis. These two parameters can be computed for different threshold values on the basis of points plotted on the graph, as results of blood pressure measurements in individuals with known health status (hypertension/no hypertension).

A cut-off point set at 0 would mean a "test" (i.e., BP measurement) with $100 \%$ sensitivity and ability to detect all patients with genuine hypertension (i.e., sustained 


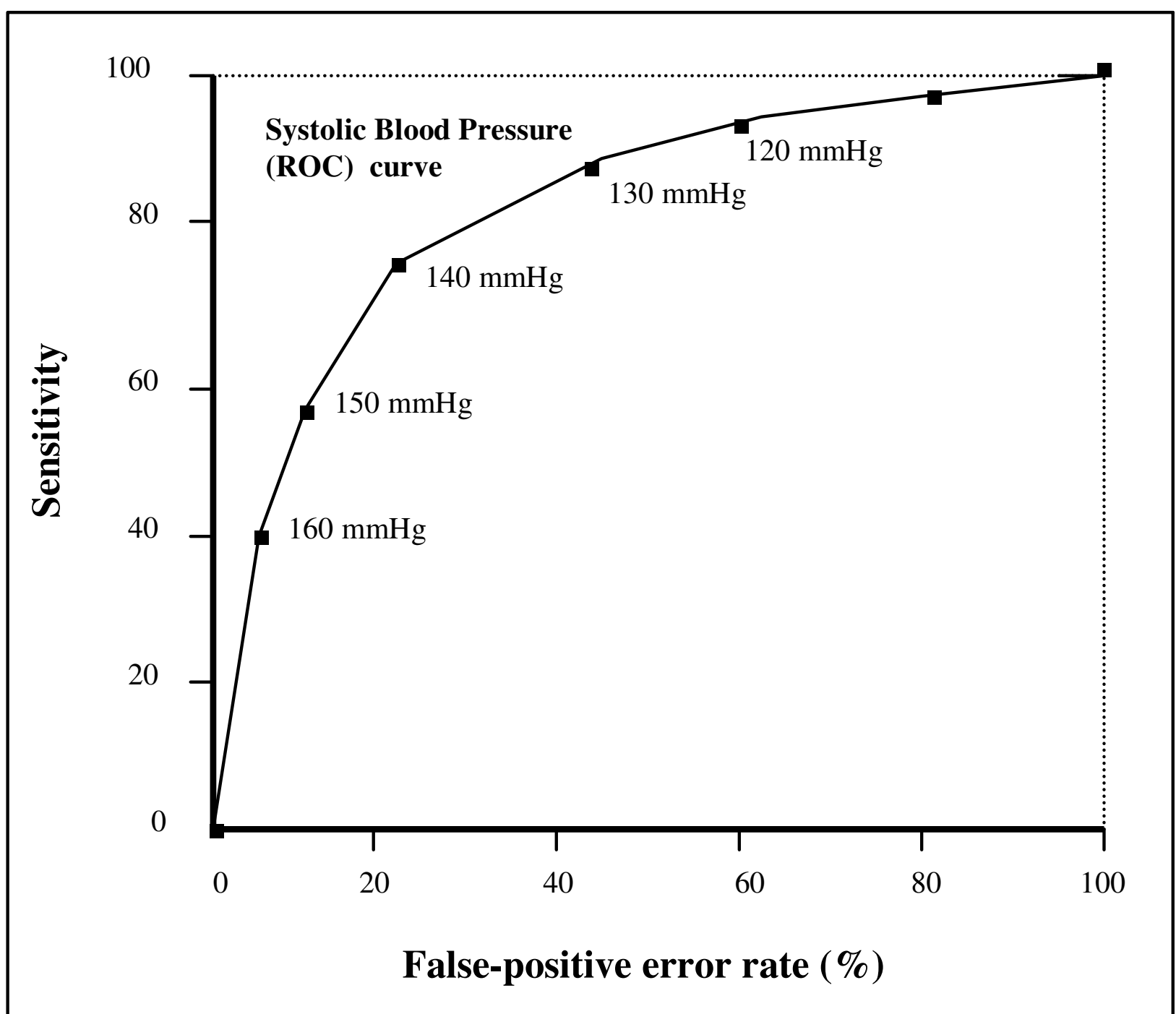

Figure 5

Receiver operating characteristic curve exploring the proper cut-off point for blood pressure measurement.

hypertension). However, all normal individuals (i.e., without hypertension) would screen positive, as reflected by a $100 \%$ false-positive error rate (overdiagnosis). The corresponding point would be placed in the right upper corner of the graph.

In the other extreme, a hypothetical cut-off point of 350 $\mathrm{mmHg}$, for example, would imply that virtually all hypertensive patients were missed (underdiagnosis), reflected by $0 \%$ sensitivity. This point would be placed in the lower left corner of the graph.
Using a similar reasoning, the sensitivity and the falsepositive error rate can be computed for increasing threshold values. Connecting the points plotted on the graph would generate a ROC curve.

As the left upper corner represents a sensitivity of $100 \%$ and $0 \%$ false-positive rate, the real best cut-off point is the one lying closest to it.

Fig. 5 suggests that the $140 / 90 \mathrm{mmHg}$ is, as a matter of fact, the best cut-off point, a fact that should satisfy all 
those who are sceptical as to the value of this particular threshold value. Obviously, its use does not preclude a refined physician-patient dialog aiming at accounting for the patients view regarding a particular antihypertensive treatment, as Campbell and Murchie put it: "Appropriate management of blood pressure should be guided by an informed dialogue between patients and doctors and not by blind pursuit of blood pressure targets"[35].

In fact, despite the drawbacks mentioned above, of an arbitrarily selected office blood pressure cut-off point for practical purposes, the office $\mathrm{BP}$ measurement as a method as such, need not be entirely discarded.

On the contrary, there are three different instances in which it may be used with certainty to decide whether to treat or not to treat patients. The first two instances are discernable from Fig. 4 and pertain to individuals without any compelling indication (i.e.., diabetes mellitus or renal dysfunction):

1). The great majority of individuals with office BP $>160$ / $95 \mathrm{mmHg}$ are genuine hypertensives. They may have sustained essential hypertension (or a secondary form of hypertension) [36]. Approximately 50\% of myocardial infarctions and one third of strokes are known to be associated with BP $>160 / 95 \mathrm{mmHg}$. The presence of one or several other risk factors further increase the certainty that these patients need pharmacological treatment and careful, long-term follow-up [5,37].

2). Likewise, the great majority of individuals with office $\mathrm{BP}<130 / 80 \mathrm{mmHg}$ are likely to be free of hypertension and/or the need for pharmacologic blood pressure lowering treatment [38]. Regular health checks, for example at two years intervals, are likely to capture propensity toward increased risk, particularly among individuals who, according to the current classification belong to the high-normal prehypertension category (130/85-139/89 $\mathrm{mmHg}$ ).

In this context, it is worth re-emphasizing that blood pressure values below the 140/90 mmHg cut-off point do not confer total protection against a cardiovascular events. Data from Framingham Study have shown that more than one half $(57 \%)$ of all heart attacks and almost one half of all strokes in some population studies occur in persons with normal office blood pressure [39-41].

3 ). The third instance pertains to patients with known diabetes mellitus and renal dysfunction. For these patients, the office blood pressure measurement functions merely as a quasi-"gold standard" test.
Fig. 6 illustrates the concept of two population distributions: one of diabetics without hypertension and another of diabetics with associated hypertension. Given the widespread consensus that patients with diabetes and associated hypertension should get pharmacological treatment whenever BP > 130/80 mmHg [42,43], the two distributions do not appear to have any degree of overlap, with the cut-off point of $130 / 80 \mathrm{mmHg}$ discriminating well between those supposed to be treated pharmacologically, from those who are not.

A justifiable question that may arise is why a somewhat lower cut-off point, i.e., $130 / 80 \mathrm{mmHg}$, can be considered as more reliable than the $140 / 90 \mathrm{mmHg}$, given that office BP measurement is likely to carry the same sort of problems in both cases.

The answer is pretty simple. An assumed overlap of the two distributions (Fig. 6), leading to FP assessments (overdiagnosis) and FNs (underdiagnosis), would cause neither diagnosis nor management concerns. Namely, patients with diabetes and associated hypertension need aggressive antihypertensive treatment meant to lower BP as much as possible [44-47]. Blood pressure measurement errors around the cut-off point value of $130 / 80 \mathrm{mmHg}$ are, therefore, likely to have neither clinical nor prognostic relevance, as long as the diabetes mellitus diagnosis is certain.

Furthermore, Fig. 6 depicts a second cut-off point relevant for the population of diabetics with associated hypertension: the $150 / 90 \mathrm{mmHg}$, which, according to current guidelines is an indication for use of combination therapy (two drugs from the start).

At closer scrutiny of the uncertainty range ( $\geq 130 / 85$ to $<160 / 95 \mathrm{mmHg}$ ) (see Fig. 7) from its lower bound upward, as assessed by office blood pressure measurements, it appears to be a mix of populations consisting of:

- Subjects with prehypertension (high-normal BP $\geq 130$ / $85-139 / 89 \mathrm{mmHg}$ )

- Patients with masked hypertension

- Subjects with white coat hypertension

- Patients with sustained hypertension

Fig. 8 attempts to depict the frequency distribution of the aforementioned patient categories in a single, common population distribution. It suggests that a great part of the total population lies either in the in the uncertainty range or under the area consisting of genuine hypertensive patients (i.e., with sustained hypertension). 


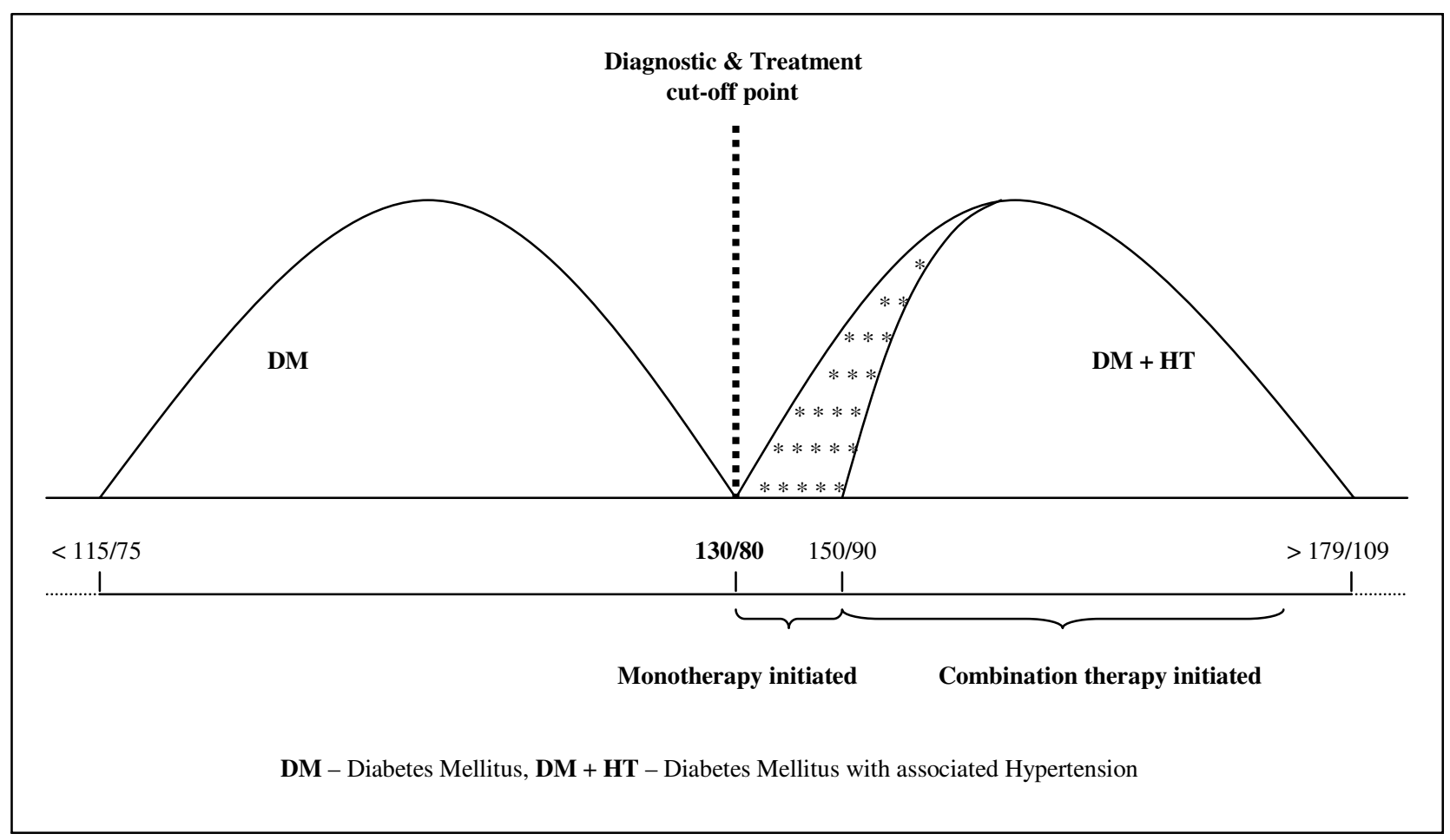

Figure 6

Hypothetical, non-overlapping distributions of diabetics and diabetics with associated hypertension patients.

A recent analysis of the worldwide global burden of hypertension [48] indicated that $26.4 \%$ of the adult population in 2000 had hypertension and that 29.2\% were projected to have the condition by 2025. The hypertension prevalence is, however, considerably much higher in economically developed countries as compared with economically developing countries (37.3\% versus $29.9 \%$ ) [48].

A multinational sample surveys carried out in six European countries, Canada and US, in the 1990s indicated the age-adjusted prevalence of hypertension was $28 \%$ in the North American countries and $44 \%$ in the European countries [24].

About 59 million American adults (29\%) fall into prehypertension category (SBP 120-139 mmHg or DBP 80-89 mmHg) [49].

Extrapolating roughly from the above figures, the prevalence of hypertension in economically developed countries $(37.3 \%)$ and the estimation of prehypertension in US (29\%) would add up to a $66.3 \%$ of the entire population having a form of hypertension or prehypertension. This average figure might be somewhat lower in America and Canada but may reach $75 \%$ in the European countries.

Furthermore, epidemiological data [50] indicate that approximately $25 \%$ of the community burden of BPrelated CVD is occurring among the population of hypertensives with systolic BP $\geq 160 \mathrm{mmHg}$ (representing only approximately $5 \%$ of the total number of hypertensives). About 33\% of all BP-related CVD events are likely to occur in the persons within normotensive $\mathrm{BP}$ range $(<140$ $\mathrm{mmHg}$ ) while more than $66 \%$ of the same burden can be attributed to the patient population with systolic BP $\geq 140$ $\mathrm{mmHg}$, i.e., belonging to the uncertainty range. Given that the lower bound of the uncertainty range extends to 130/ $85 \mathrm{mmHg}$ (to include the high-normal prehypertension), it might encompass as much as $80 \%$ of the total community burden of BP-related CVD risk.

\section{Prehypertension (PH)}

The new JNC-7-hypertension category [49] was subject to heavy criticism, primarily by European scientists who argued that the new entity might have negative psychological impact and generate a wave of more or less unnecessary investigations in fairly healthy individuals. 


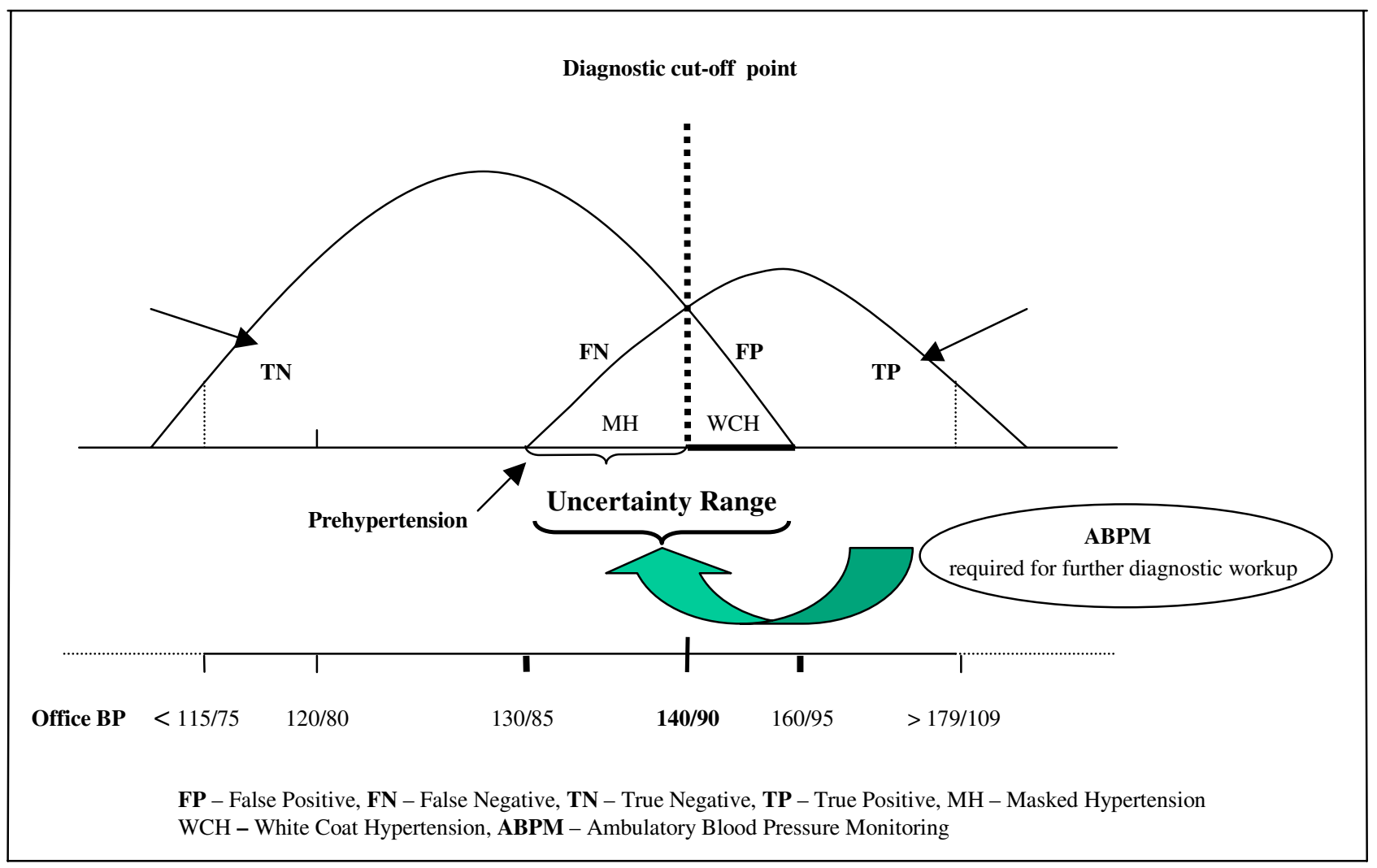

Figure 7

The uncertainty range and its mix of hypertension categories. Accurate diagnosis is only possible by ABPM.

This is, certainly, not a strong argument even if it may contain a grail of truth. Obviously, the sudden and unexpected awareness that one, despite knowing him/ herself to be in good health, belong to a group of people "at risk for heart disease", might trigger a more or less uncomfortable feeling.

However, people with BP values in the range of 130-139/ 85-89 mmHg, known to have high normal blood pressure and labelled as being prehypertensives, are also known to run a considerable higher risk for cardiovascular disease than people with optimal $(<120 / 80 \mathrm{mmHg})$ and with normal BP (120-129/80-84 mmHg) [49,51,52].

In a survey of 9845 Framingham Heart Study participants over a 4 -year period, $43 \%$ of the total of 1907 individuals (19\% of the original sample) who had high-normal blood pressure at the initial screening have developed hypertension [53]. In contrast, only $6 \%$ of the subjects with optimal blood pressure and $20 \%$ of those with normal blood pressure have developed hypertension [53]. Hypertension incidence in all three categories increased with age, reaching 37\% among subjects with high-normal BP who were 35-64 years old and 50\% among subjects aged 65 or older, likewise, with high-normal blood pressure at screening. Worthwhile emphasizing, about $15 \%$ of the subjects with high-normal blood pressure have progressed to stage II or greater degree of hypertension over 4 years of follow-up.

Overall, compared with optimal blood pressure, high-normal blood pressure was associated with a 5- (age 35-64 years) to 12-fold (age 65 years or over) elevated odds of hypertension on follow-up [53], justifying inclusion of these subjects in the uncertainty area and thereby, the consequent need for accurate diagnosis from the outset as well as appropriate long-term management of these individuals.

\section{Masked Hypertension (MH)}

As depicted by Fig. 7, individuals with $\mathrm{MH}$ fall into the false negative area of the uncertainty range, suggesting that the condition per se is perceived as normotension as 


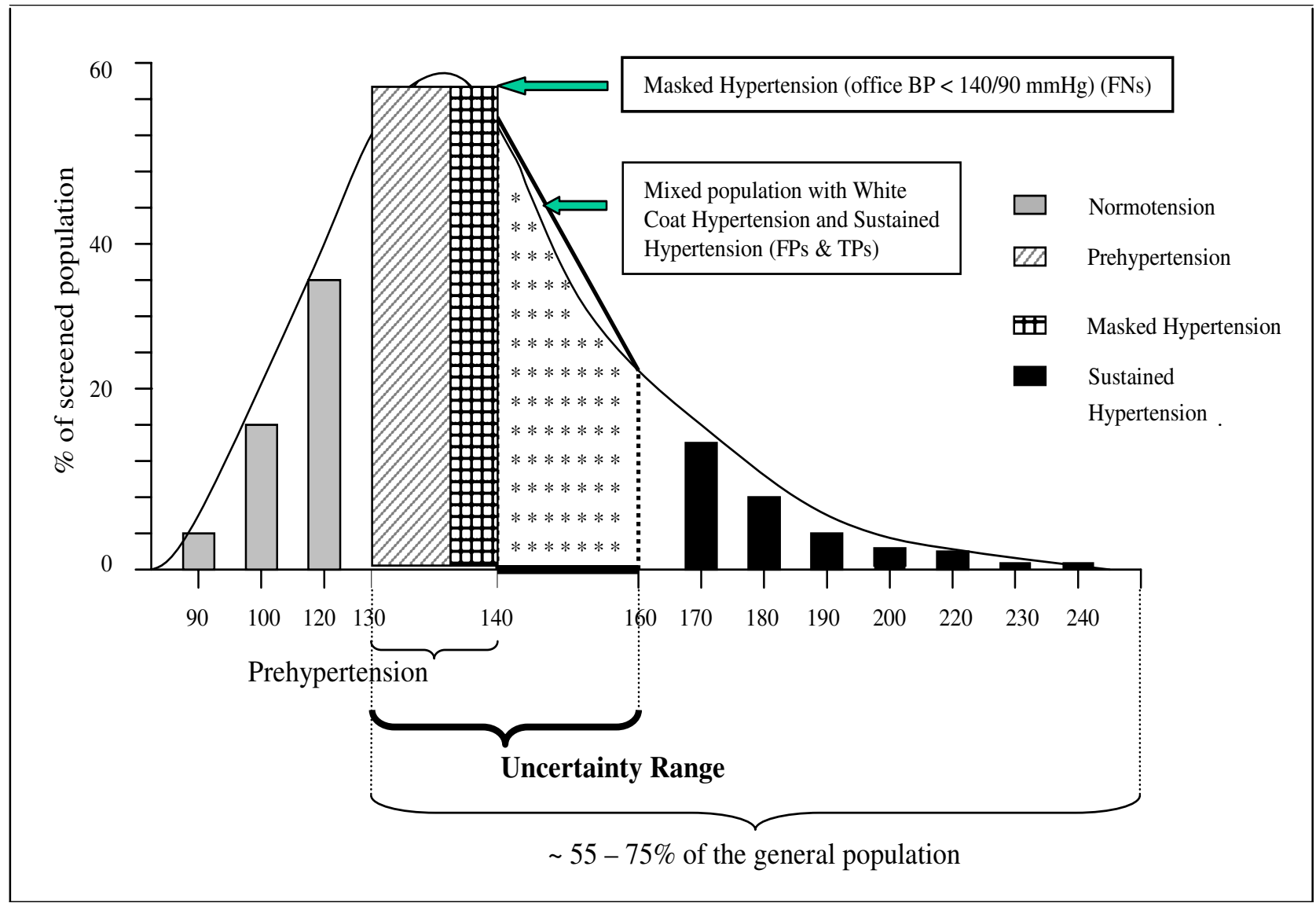

Figure 8

Frequency distribution of hypertensive categories as parts of a common, normal distribution.

assessed by office blood pressure measurement. However, $\mathrm{MH}$ is genuine hypertension, as assessed by daytime ABP of $>135 / 85 \mathrm{mmHg}$ [54-58].

The reported prevalence rates of $\mathrm{MH}$ are 9\% [59], 14\% [60], 23\% [61] and 31\% [62]. Individuals with masked hypertension were shown to be similar with true hypertensive patients in terms of left ventricular characteristics, carotid artery wall thickness, and prevalence of discrete atherosclerotic plaques [63] but to be different on several demographic and lifestyle variables (greater proportion of males, older, greater degree of alcohol consumption, past smoking) $[60,63]$.

Missed diagnosis of $\mathrm{MH}$ in these patients leaves them untreated and at risk for long-term consequences of hypertension.
Selenta et al. [60] have demonstrated that the BP values falling in the borderline range $(10 \mathrm{mmHg}$ above and below 140/90 $\mathrm{mmHg}$ ) are particularly inaccurate. Most participants presumed healthy in the $10 \mathrm{mmHg}$ range below 140/90 mmHg have hypertensive ABP, i.e., $\mathrm{MH}$, commonly missed by the office BP measurement. The authors of the same article concluded that only those office readings averaging 20 points above or below the $140 / 90 \mathrm{mmHg}$ cut-off, represent safe diagnostic information.

The high prevalence rates of $\mathrm{MH}$ and the high level of misdiagnosis rate by office BP measurement of the condition calls for generalization of ABPM use in clinical practice, for diagnosis and management purposes of this large patient population. 


\section{White coat hypertension (WCH)}

Subjects with white coat hypertension have a normal average daytime blood pressure outside a medical setting $[64,65]$ but present with high BP in the medical environment $[66,67]$. By definition $[68,69]$, white coat hypertension is diagnosed as such, if the conventional BP is persistently $\geq 140 / 90 \mathrm{mmHg}$ and the average daytime ambulatory BP is below 135/85 $\mathrm{mmHg}$.

The prevalence rate of the $\mathrm{WCH}$ is reported to be in the area of 15 to $35 \%$ of patients in whom hypertension is diagnosed $[70,71]$ and in nearly $30 \%$ of pregnant women [72].

The use of a distinct cut-off point is important for diagnostic and management purposes. It also distinguishes WCH from the white coat effect, the latter being a quantitative measure of the blood pressure rise in the presence of a physician. This transient blood pressure rise has been quantified by Mancia et al. [73] who demonstrated mean value increases of $27 \mathrm{mmHg}$ for both systolic and diastolic pressure when measurement was done in the presence of a physician. The white coat effect is commonly defined as an office BP exceeding mean daytime ambulatory BP by at least $20 \mathrm{mmHg}$ systolic and/or $10 \mathrm{mmHg}$ diastolic [74]. Such a large white coat effect has been found in as many as $73 \%$ of treated hypertensive subjects and it may occur more frequently in women than in men $[75,76]$.

As illustrated by Fig. 7, both WCH as a distinct entity and the white coat effect as a transitory $\mathrm{BP}$ rise, fall into the false positive area of the uncertainty range, i.e., beyond the $140 / 90 \mathrm{mmHg}$ cut-off point as assessed by office BP measurement, and count thereby as overdiagnosis.

Indeed, the consequences of failing to identify white coat hypertension are considerable. People may be penalized for insurance and pension policies, and for employment [77].

Long-term treatment may be prescribed unnecessarily with all the risks derived from potential treatment-emergent adverse reactions [78-80].

Given the seriousness as well as the high risk for such consequences in the clinical practice, several hypertension guidelines recommend use of ABPM for diagnosis of WCH [81-83].

In 2001, the CMS in USA has selected "patients with suspected WCH" as having indication for ABPM, with the use of method itself being reimbursed [84].

Speculations on what clinical characteristics might suggest the presence of WCH and thereby the need for ABPM, in an attempt to preclude indiscriminate use of the method, is certainly not justified anymore [85]. On the contrary, current evidence argues in favour of ABPM use in all patients with office blood pressure falling in the uncertainty range ( $\geq 130 / 85$ to $<160 / 95 \mathrm{mmHg})$.

Once WCH has been diagnosed, ABPM should be repeated at annual or biannual intervals [86] with the aim to capture increased cardiovascular risk that would justify initiation of drug treatment $[87,88]$.

\section{A holistic approach toward hypertension management}

Fig. 7 suggests that ABPM should be used for further diagnostic work up of subjects whose office-measured BP values fall in the uncertainty range. Indeed, combining office blood pressure (OBP) measurement values with ABPM recording results (daytime normality cut-off point of 135/ $85 \mathrm{mmHg}$ ) allows for discrimination among the following diagnostic entities (see Fig. 9):

- Sustained Hypertension (SH) - (ABPM > 140/90 and OBP $\geq 140 / 90$ )

- Masked Hypertension $(\mathrm{MH})$ - $(\mathrm{ABPM}>135 / 85$ and $\mathrm{OBP}<140 / 90)$

- White Coat Hypertension (WCH) - (ABPM < 135/85 and $\mathrm{OBP} \geq 140 / 90$ )

- Prehypertension (high-normal BP) (PH) - (ABPM < 135/ 85 and OBP 130/85-139/89)

The specific thresholds used for diagnostic discriminatory purposes can also be used for management purposes. It is widely agreed that poor control of hypertension is defined by $\mathrm{BP}$ values $>140 / 90 \mathrm{mmHg}$ [89] while good control, in terms of ABPM, counts $\leq 135 / 85 \mathrm{mmHg}$ [90-92]. Likewise, there is widespread agreement that patients with clinic pressures of $=160 / 95 \mathrm{mmHg}$ need drug treatment [93].

The well-known, multifactorial inaccuracies imbedded in the office blood pressure measurement and, in contrast to that, the widespread agreement as to the superiority and multi-purpose use of ABPM [94-102], as well as reports on its cost-effectiveness [103] [104], make the method to emerge as an additional alternative to the conventional approach of hypertension management. While ABPM can, on no account, be a replacement for the conventional office blood pressure measurement, it is increasingly obvious that its use is a sine qua non condition for accurate diagnosis and management of subjects belonging to a large segment of the general population displaying 


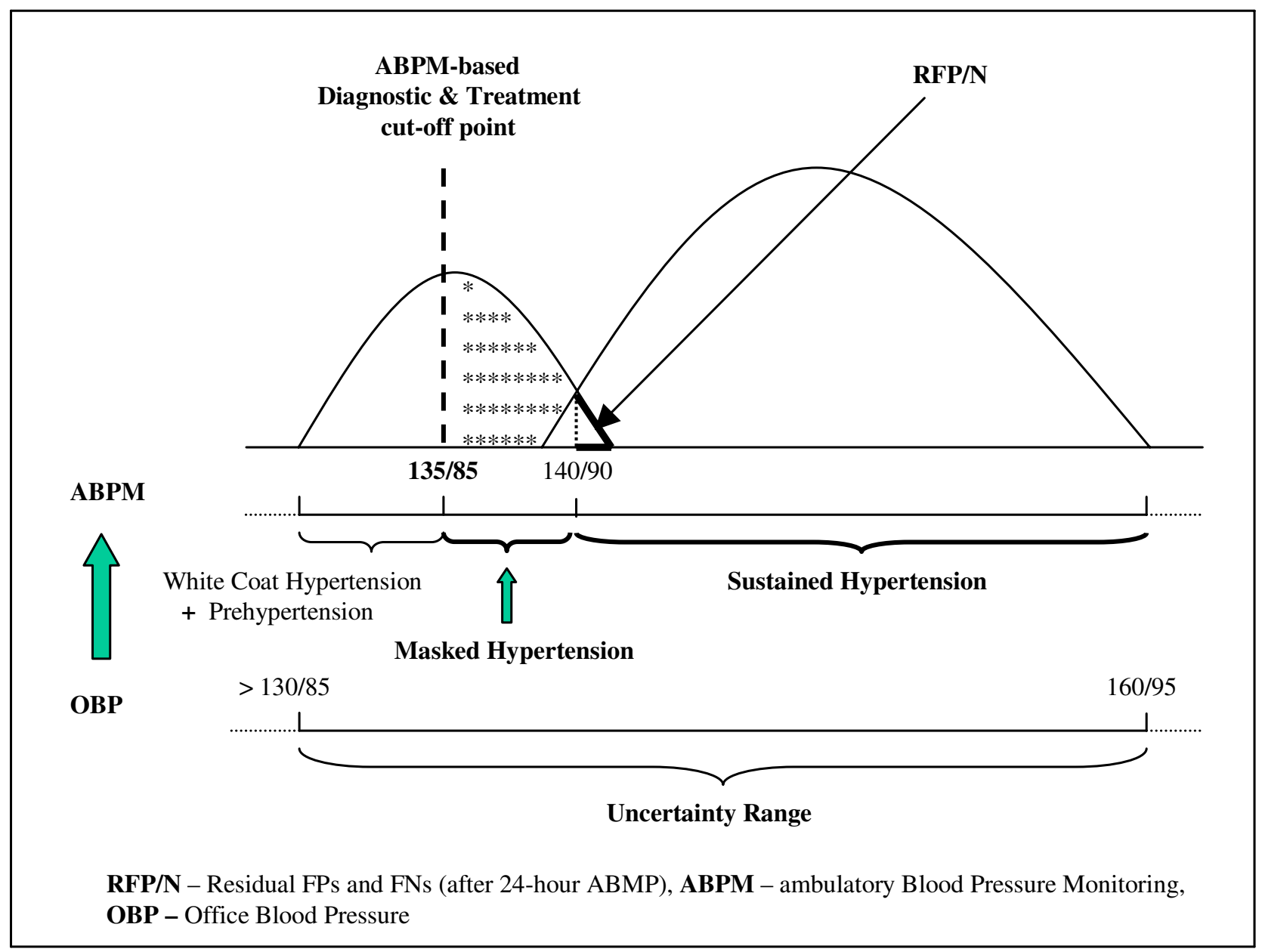

Figure 9

ABPM assessment of subjects with BP values falling in the uncertainty range.

different forms of high blood pressure-related entities (falling in the uncertainty range).

More recent studies provide evidence that the ABP testing is generally well-accepted and tolerated by patients. A survey of 177 patients, who underwent ABPM in primary care office setting in US over a 2.5 years period [103], showed that $75 \%$ of them considered the 24-hour ABPM test as worthwhile, with respect to the time and money incurred by the investigation. Ninety per cent of the patients thought that the results of the test were to provide useful information for the physician's decision making on appropriate therapy. Similar results were derived from a qualitative study of ABPM in UK [71]. Both studies have emphasized, however, the importance of the explanation given by the physician to the patient as to the benefit of undergoing ABPM testing, in order to minimize the perception of discomfort related to the 24 -hour recording.

Fig. 10 is an algorithmic approach to the management of all subjects who display office blood pressure falling in the uncertainty range ( $\geq 130 / 85$ to $<160 / 95 \mathrm{mmHg}$ ). The top part of the figure suggests that two different units are involved in the management/investigation of such patients, a usual GP or specialist office and a laboratory specialised in ABPM recordings and results interpretation.

An initial assessment is commonly performed in the GP's office where blood pressure is recorded, according to current guidelines, by the physician or a trained nurse. Patients whose average $\mathrm{BP}$, derived from two 


\section{Hypertension Management (GP Office/Hypertension Clinic) \\ ABPM \\ (Local or Central Lab.)}

\section{Office Management}

- Follow-up biannually with ABPM

- ABSOLUTE RISK Assessment (Evaluation for RF/TOD)

- Drug Treatment tailored to individual patient

- Follow-up with OBP

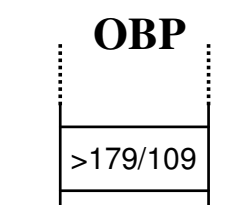

24-hour ABPM

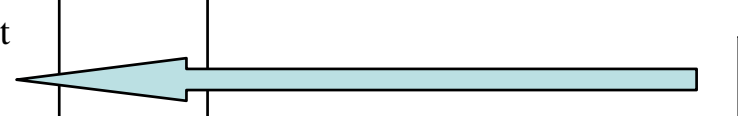

MH

- Lifestyle modification

- Annual follow-up with OBP

- Annual follow-up with ABPM

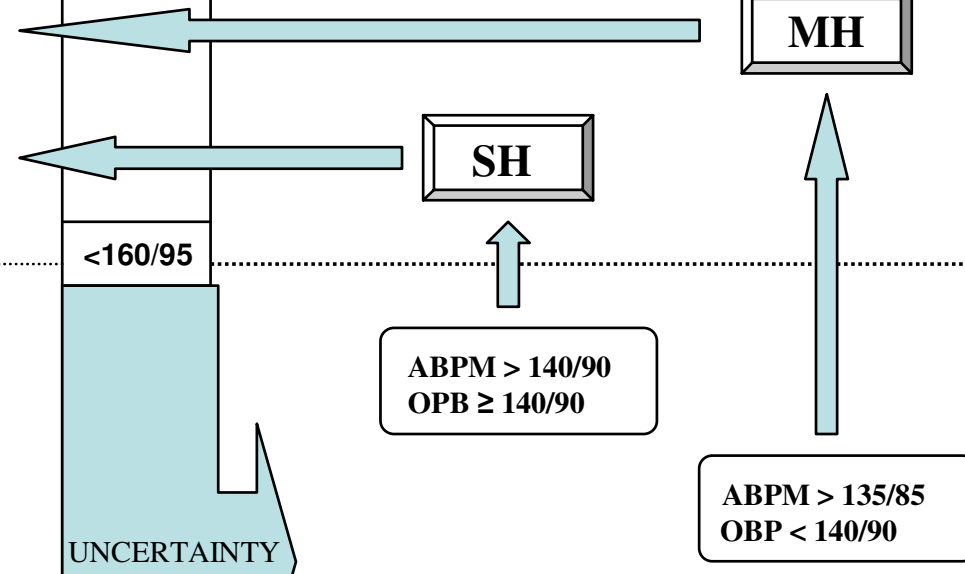

ABPM $<135 / 85$

OBP $\geq 140 / 90$

ABPM $<135 / 85$

OBP 130/85-139/89
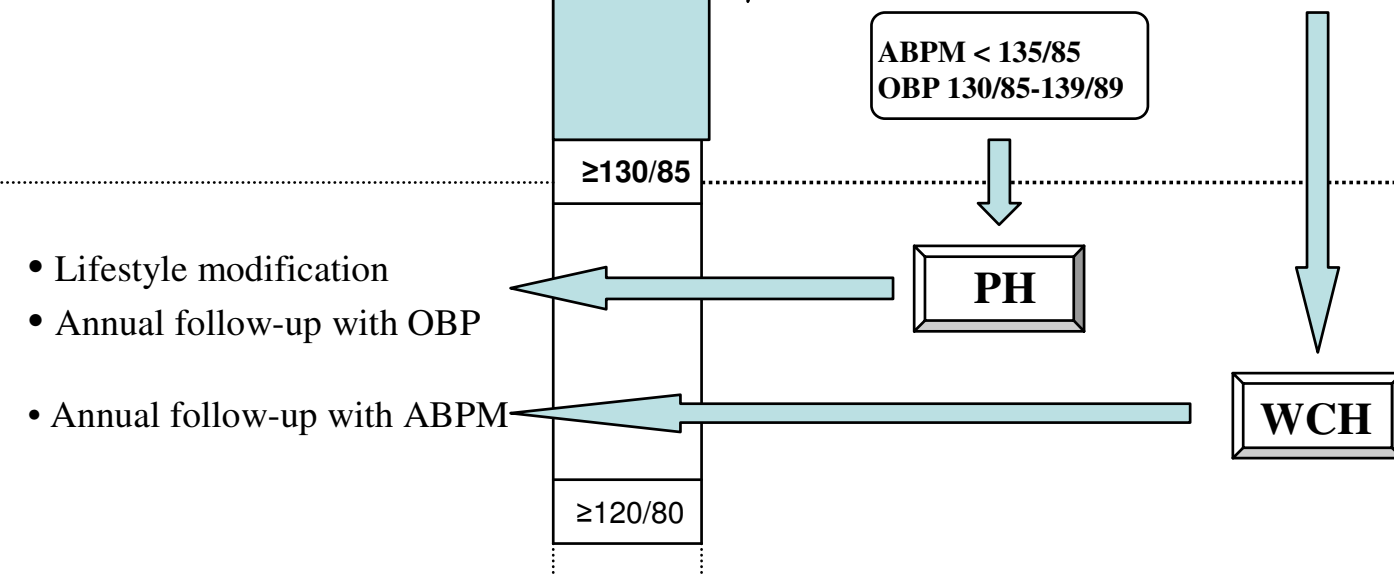

OBP - Office Blood Pressure, ABPM - Ambulatory Blood Pressure Monitoring, SH - Sustained Hypertension, MH - Masked Hypertension, PH - Prehypertension, WCH - White Coat Hypertension, RF - Risk Factors for CVD, TOD - Target Organ Damage

\section{Figure 10}

An algorithmic approach to management of subjects with $\mathrm{OBP}$ in the uncertainty range $(\geq 130 / 85$ to $<160 / 95 \mathrm{mmHg})$. 
measurements per visit, in two or several visits, lies in the uncertainty range should be referred for 24-hour ABP monitoring.

The result of the daytime ABPM assessed together with the OBP generates a diagnostic conclusion matching one of the following alternatives: $\mathrm{SH} / \mathrm{MH} / \mathrm{WCH}$ or $\mathrm{PH}$ (high-normal level).

Amazingly, the current conventional cut-off point of 140/ $90 \mathrm{mmHg}$ looses entirely its value for decision making, at least in the initial stage assessment.

Indeed, as mentioned above, much information may be lost when sensitivity and specificity are defined in relation to a single cut-off point value of a continuous variable (such as the BP). Instead, using a range, i.e., the interval between two cut-off points ( $\geq 130 / 85$ to $<160 / 95 \mathrm{mmHg}$ ) for further decision making, avoids the well-known diagnostic uncertainties.

The 140/90 cut-off point retains, however, its (arbitrary) value in the next stage of ABPM investigation. The value of the OBP, whether below or above the 140/90 mmHg threshold is corroborated with the ABPM result for selection of one out of four different diagnostic alternatives: sustained hypertension, masked hypertension, white coat effect or high-normal prehypertension.

Once diagnosed, the patient returns to his/her physician who remains in charge with the further management decision whatever the diagnosis might be (including lifestyle changes, drug treatment, follow-up, etc.).

Obviously, diagnosis and management of patients who have any form of symptomatic atherosclerotic vascular disease including previous myocardial infarction, by pass graft surgery, angina, stroke or transient ischaemic attack, peripheral vascular disease or atherosclerotic renovascular disease, need treatment of even mild hypertension ( $\geq$ $140 / 90 \mathrm{mmHg}$ ) for secondary prevention. Likewise, patients with target organ damage such as LVH, heart failure, proteinuria or renal impairment need treatment of even very mild hypertension.

Patients with type I and II diabetes mellitus and associated mild hypertension ( $\geq 130 / 80 \mathrm{mmHg}$ ) generally have diabetic nephropathy and should be treated.

All the aforementioned compelling indications require drug treatment for any level of raised blood pressure.

This translates in the need to apply the algorithm in Fig. 10 and perform formal absolute risk assessment only in patients with uncomplicated hypertension (i.e., with BP values falling in the uncertainty range $\geq 130 / 85$ to $<160 / 95$ $\mathrm{mmHg}$ ).

\section{Conclusion}

Accurate diagnosis and management of high blood pressure is of paramount importance for the prevention of long-term, cardiovascular, cerebrovascular and renal complications. Aggressive attempts to identify and treat "high blood pressure values" must be balanced carefully with the risks of overdiagnosis and overtreatment in these patients.

ABPM has a proven value not only as a research tool but also as a valuable investigative method for a large segment of the hypertensive population belonging to the uncertainty range.

Practical management of these patients, once accurate diagnosis has been established, should be based on absolute cardiovascular disease risk and on a risk-communication dialog between the physician and patient as well as on their mutual agreement regarding the specific treatment to be initiated and the appropriate long-term follow-up.

\section{Competing interests}

The author(s) declare that they have no competing interests.

\section{References}

I. 2003 European Society of Hypertension - European Society of Cardiology guidelines for the management of arterial hypertension. Journal of Hypertension 2003, 21 : 10 II- 1053.

2. World Health Organization, International Society of Hypertension Writing Group: 2003 World Health Organization (WHOI International Society of Hypertension (ISH) statement on management of hypertension. J Hypertens 2003, 21:1983-1992.

3. Anderson KV, Odell PM, Wilson PWF, Kannel WB: Cardiovascular disease risk profiles. Am Heart J 1991, I 2 1:293-298.

4. Jackson RJ, Lawes CMM, Bennett DA, Milne RJ, Rodgers A: Treating Individuals 5: Treatment with drugs to lower blood pressure and blood cholesterol based on an individual's absolute cardiovascular risk. Lancet 2005, 365:434-44I.

5. Volpe M, Alderman MH, Furberg CD, Jackson R, Kostis JB, Laragh JH, Psaty BM, Ruilope LM: Beyond hypertension. Toward guidelines for cardiovascular risk reduction. Am J Hypertens 2004, I7(I I): 1068-1074.

6. Mancia G, Grassi G: Systolic and diastolic blood pressure control in antihypertensive drug trials. J Hypertens 2002, 20: $|46|-\mid 464$.

7. Prospective Studies Collaboration: Age-specific relevance of usual blood pressure to vascular mortality: a meta-analysis of individual data for one million adults in 61 prospective studies. Lancet 2002, 360:1903-1913.

8. Law MR, Wald NJ: Risk factor thresholds: their existence under scrutiny. BMJ 2002, 324:1570-1576.

9. Rodgers A: Quantifying selected major risks to health. In The world health report 2002: reducing risks, promoting healthy life Edited by: Murray CJL, Lopez Ad. Geneva: WHO; 2002:47-92.

10. Neaton JD, Wenthworth D, for the Multiple Risk Factor Intervention Trial Research Group: Serum Cholesterol, blood pressure, cigarette smoking, and death from coronary heart disease. Overall findings and differences by age for 316,099 white men. Arch Intern Med 1992, 152:56-54. 
11. Asia Pacific Cohort Studies Collaboration: Cholesterol, coronary heart disease and stroke in the Asia Pacific Region. Int J Epidemiol 2003, 32:563-572.

12. Asia Pacific Cohort Studies Collaboration: Blood pressure and Cardiovascular disease in the Asia Pacific Region. J Hypertens 2003, 2 I:707-716.

13. Eastern Stroke and Coronary Heart Disease collaborative Research Group: Blood pressure, cholesterol, and stroke in Eastern Asia. Lancet 1998, 352:|80|-1807.

14. William BW: Ambulatory blood-pressure monitoring in clinical practice. New Engl J Med 2003, 348(24):2377-2378.

15. Little P, Barnet J, Barnsley L, Marjoram J, Fitzgerald-Baron A, Mant D: Comparison of agreement between different measures of blood pressure in primary care and daytime ambulatory blood pressure. BMJ 2002, 325:254-259.

16. Bellomo G, Narducci PL, Rondoni F, Pastorelli G, Stagnoni G: Prognostic value of 24-hour blood pressure in pregnancy. JAMA 1999, 282: |447-|452.

17. Staessen JA, Fagard R, Thjis L: Randomized double-blind comparison of placebo and active treatment for older patients with isolated systolic hypertension. Lancet 1997, 350:757-764.

18. O'Brian E: Ambulatory blood pressure monitoring in the management of hypertension. Heart 2003, 89:57|-576.

19. MacDonald MB, Laing GP, Wilson MP, Wilson TW: Prevalence and predictors of white-coat response in patients with treated hypertension. Can Med Assoc J 1999, I 6 I:265-269.

20. Pickering T, Davidson K, Gerin W: Masked hypertension. Hypertension 2002, 40:795-796.

21. Guillaume B, Chatellier G, Genes N, Vaur L, Vaisse B, Menard J, Mallion JM: Cardiovascular prognosis of "Masked Hypertension" detected by blood pressure self-measurement in elderly treated hypertensive patients. JAMA 2004, 29 I : I 342-1349.

22. Guillaume B, Chatellier G, Genes N, Vaur L, Vaisse B, Menard J, Mallion JM: Cardiovascular prognosis of "Masked Hypertension" detected by blood pressure self-measurement in elderly treated hypertensive patients. JAMA 2004, 29 I: I 342- I349.

23. Mulrow PJ: Hypertension: a worldwide epidemic. In Hypertension primer: the essentials of high blood pressure 2 nd edition. Edited by: Izzo JL, Black HR, Goodfriend TL. Baltimore: Williams and Wilkins; 1999:72|-273.

24. Wolf-Maier K, Cooper RS, Banegas JR, Gianpaoli S, Hense HW, Joffres $M$, Kastarinen $M$, Poulter N, Primatesta $P$, Rodriguez-Artalejo $F$ Stegmayr B, Thamm M, Tuomilehto J, Vanuzzo D, Vescio F: Hypertension Prevalence and blood pressure levels in 6 European countries, Canada, and the United States. JAMA 2003, 289:2363-2369.

25. Kotchen JM, McKean HE, Kotchen TA: Blood pressure trends with aging. Hypertension 1982, 4(suppl 3): I I-I 29.

26. Franklin SS, Larson MG, Khan SA: Does the relation of blood pressure to coronary heart disease risk change with aging? The Framingham Heart Study. Circulation 200I, I 03: I 245- I 249.

27. Pitt B, Julian D, Pocock S: Clinical Trials in Cardiology WB Saunders Company Ltd., London; 1997.

28. Mower WR: Evaluating bias and variability in diagnostic test reports. Ann Emerg Med 1999, 33:85-91.

29. Patterson RA, Horowitz SE: Importance of epidemiology and biostatistics in deciding clinical strategies for using diagnostic tests: a simplified approach using examples from coronary artery disease. J Am Coll Cardiol 1989, I3:I653.

30. William BW: Ambulatory blood-pressure monitoring in clinical practice. New Engl J Med 2003, 348(24):2377-2378.

31. Kottke TE, Stroebel R, Hofman R: JNC-7 it's more than high blood pressure. JAMA 2003, 289(I 9):2573-2575.

32. Mulrow PJ: Hypertension: a worldwide epidemic. In Hypertension primer: the essentials of high blood pressure 2 nd edition. Edited by: Izzo JL, Black HR, Goodfriend TL. Baltimore: Williams and Wilkins; 1999:721-723.

33. Jekel JF, Elmore JG, Katz DL: Epidemiology Biostatistics and Preventive Medicine WB Saunders Company Ltd., Philadelphia; 1996.

34. Mayer D: Essential Evidence-Based Medicine Cambridge University Press, Cambridge; 2004.

35. Campbell NC, Murchie P: Treating hypertension with guidelines in general practice. $B M J$ 2004, 329:523-524

36. Wong ND, Black HR, Gardin JM: Preventive Cardiology McGraw Hill companies, Inc., New York; 2000
37. Alderman M: Blood Pressure Measurement. Individualized Treatment Based on Absolute Risk and the Potential for Benefit. Ann Intern Med 1993, I I 9:329-335.

38. Prospective Studies Collaboration: Age-specific relevance of usual blood pressure to vascular mortality a meta-analysis of individual data for one million adults in $6 \mathrm{I}$ prospective studies. Lancet 2002, 360:9343.

39. Alderman MH: Blood Pressure Management: Individualized Treatment Based on Absolute Risk and Potential for Benefit. Ann Intern Med 1993, I I 9:329-335.

40. Kannel WB: Some lessons in cardiovascular epidemiology from Framingham. Am / Cardiol 1976, 37:269-28I.

41. Kannel WB, Wolf PA, Verter J, McNamara PM: Epidemiologic assessment of the role of blood pressure in stroke. The Framingham Study. JAMA 1970, 2 I 4:301-310.

42. Arauz-Pacheco C, Parrott MA, Raskin P: The Treatment of hypertension in adult patients with diabetes. Diabetes Care 2002 , 25(I): I34-147.

43. Bakris GL, Weir MR: Achieving goal blood pressure in patients with type 2 diabetes: combination versus fixed-dose combination approaches. J Clin Hypertens 2003, 5(3):202-209.

44. Deedwania PC: Hypertension and diabetes: new therapeutic options. Arch Intern Med 2000, 160:1 585-1594.

45. American Diabetes Association: American diabetes Association: clinical practice recommendations 2002. Diabetes Care 2002, 25(suppl I):SI-SI47.

46. Staessen JA, Wang JG, Thijs L: Cardiovascular protection and blood pressure reduction: a meta-analysis. Lancet 200I, 358: $1305-13 \mid 5$

47. Gradman $\mathrm{AH}$, Acevedo $\mathrm{C}$ : Evolving strategies for the use of combination therapy in hypertension. Curr Hypertens Rep 2002 , 4(5):343-349.

48. Kearney PM, Whelton M, Reynolds K, Muntner P, Whelton PK, He J: Global burden of hypertension: analysis of worldwide data. Lancet 2005, 365:217-223.

49. Chobanian AV, BAkris GL, Black HR, Joint National Committee on Prevention, Detection, Evaluation, and Treatment of High Blood Pressure, National Heart, Lung, and Blood Institute; National High Blood Pressure Education Program Coordinating Committee: Seventh Report of the Joint National Committee on Prevention, Detection, Evaluation, and Treatment of High Blood Pressure. Hypertension 2003, 42: I 206- 1252.

50. Stamler J, Stamler R, Neaton JD: Blood pressure, systolic and diastolic, and cardiovascular risks. US population data. Arch Intern Med 1993, 1 53:598-625.

51. World Health Organization-International Society of Hypertension Guidelines for Management of Hypertension. Guidelines Subcommittee. J Hypertens 1999, 17:151- 83.

52. Hotline Editorial: Rates of progression to hypertension among non-hypertensive subjects: implications for blood pressure screening. Eur Heart J 2002, 23:6067-1070.

53. Vasan RS, Larsan MG, Leip EP, Kannel WB, Levy D: Assessment of frequency of progression to hypertension in non- hypertensive participants in the Framingham Heart Study: a cohort study. Lancet 2001, 358: I682-1686.

54. Pickering TG: Utility of 24-hour ambulatory blood pressure monitoring in clinical practice. Can J Cardiol I995, I I:43H-48H.

55. Staessen J, Fagard R, Lijnen P, Thijs L, van Hoof R, Amery A: Ambulatory blood pressure monitoring in clinical trials. J Hypertens Suppl 199I, 9(suppl I):SI3-SI9

56. Staessen J, Fagard R, Lijnen P, Thijs L, van Hoof R, Amery A: Reference values for ambulatory blood pressure: a meta-analysis. J Hypertens 1990, 8(suppl 6):S57-S64.

57. O'Brien E, Murphy J, Tyndall A: Twenty-four-hour ambulatory blood pressure in men and women aged 17 to 80 years: the Allied Irish Bank Study. J Hypertens 1990, 9:355-360.

58. ISH Scientific Committee: Consensus document on non-invasive ambulatory blood pressure monitoring. J Hypertens 1990, 8(suppl 6):SI36-SI40.

59. Sega R, Trocino G, Lanzarotti A, Carugo S, Cesana G, Schiavina R Valagussa F, Bombelli M, Giannattasio C, Zanchetti A, Mancia G: Alterations of cardiac structure in patients with isolated office, ambulatory, or home hypertension: data from the general population (Pressione Arteriose Monitorate E Loro Associazioni [PAMELA] Study). Circulation 2001, 1 04: 1385-1392 
60. Selenta C, Hogan BE, Linden W: How Often Do Office Blood Pressure Measurements Fail to Identify True Hypertension? An Exploration of White-Coat Normotension. Arch Fam Med 2000, 9:533-540.

61. Prisant LM: Ambulatory blood pressure monitoring in the diagnosis of hypertension. Cardiol Clin 1995, 13:479-490.

62. O'Brien E, Mee F, Atkins N, O'Malley K: Accuracy of the Spacelabs $\mathbf{9 0 2 0 7}$ determined by the British Hypertension Society Protocol. J Hypertens 199|, 5:573-574.

63. Liu JE, Roman MJ, Pini R, Schwartz JE, Pickering TG, Devereux RB: Elevated ambulatory with normal clinic blood pressure ("white coat normotension") is associated with cardiac and arterial target organ damage. Ann Intern Med 1999, I 3 I:564-572.

64. Pickering TG, James GD, Boddie C, Harsfield GA, Blank S, Laragh JH: How common is white-coat hypertension? JAMA 1988, 259:225-228.

65. Staessen JA, Thijs L, Fagard R, for the Systolic Hypertension in Europe Trial Investigators, et al.: Predicting cardiovascular risk using conventional vs ambulatory blood pressure in older patients with systolic hypertension. JAMA 1999, 282:539-546.

66. White WB, Schulman P, McCabe EJ, Dey HM: Average daily blood pressure, not office pressure, determines cardiac function in patients with hypertension. JAMA 1989, 26 I:873-877.

67. Mancia G, Zanchetti A: White-coat hypertension: misnomers, misconceptions and misunderstandings. What should we do next? J Hypertens 1996, 14: 1049-1052.

68. Verdecchia P, Clement D, Fagard R, Palatini P, Parati G: Target organ damage, morbidity and mortality. Blood Pressure Monitoring 1999, 4:303-317.

69. Pickering TG, Coats A, Mallion JM, Mancia G, Verdecchia P, Task Force V: White-coat hypertension. Blood Pressure Monitoring 1999, 4:333-341.

70. William BW: Ambulatory blood-pressure monitoring in clinical practice. New Engl J Med 2003, 348(24):2377-2378.

7I. Little P, Barnet J, Barnsley L, Marjoram J, Fitzgerald-Baron A, Mant D: Comparison of agreement between different measures of blood pressure in primary care and daytime ambulatory blood pressure. BMJ 2002, 325:254-259.

72. Bellomo G, Narducci PL, Rondoni F, Pastorelli G, Stagnoni G: Prognostic value of 24-hour blood pressure in pregnancy. JAMA 1999, 282: | 1447-| 452 .

73. Mancia G, Bertineri G, Grassi G: Effects of blood pressure measured by the doctor on patient's blood pressure and heart rate. Lancet 1983, 2:695-698.

74. Myers MG, Haynes B, Rabbkin SW: Canadian Hypertension Society Guidelines for Ambulatory Blood Pressure Monitoring. Am J Hypertens 1999, 1 2: I | 49-1 I57.

75. Myers MG, Reeves RA: White-coat phenomenon in patients receiving antihypertensive therapy. Am J Hypertens 1991, 4:844-849

76. Myers MG, Reeves RA: White-coat effect in treated hypertensive patients: sex difference. J Hum Hypertens 1995, 9:729-733.

77. O'Brien E: Ambulatory blood pressure monitoring in the management of hypertension. Heart 2003, 89:57I-576.

78. Brawn LA, Castleden CM: Adverse drug reactions: an overview of special considerations in the management of the elderly patient. Drug Safety 1990, 5:42I-435.

79. Rochon PA, Anderson GM, Tu JV: Age- and gender-related use of low-dose drug therapy: the need to manufacture low-dose therapy and evaluate the minimum effective dose. J Am Geriatr Soc 1999, 47:954-959.

80. Tomlinson B: Optimal dosage of ACE inhibitors in older patients. Drugs Aging 1996, 9:262-273.

81. Joint National Committee on Detection, Evaluation, and Treatment of High Blood Pressure: The Sixth Report of the Joint National Committee on detection, evaluation, and treatment of high blood pressure. Arch Intern Med 1997, I 57:24I 3-I 446.

82. Guidelines Subcommittee: 1999 WHI/ISH Guidelines for the management of hypertension. J Hypertens 1999, I7:151-183.

83. Ramsay LE, Williams B, Johnston GD, MacGregor GA, Poston L, Potter JF, Poulter NR, Russel G: British Hypertension Society Guidelines for hypertension management 1999: summary. $\mathrm{Br}$ Med J 1999, 5 I 9: 17630-635.

84. Centers for Medicare \& Medicaid Services: Medicare coverage policy - decisions. ABPM monitoring (\#CAG-00067N) 200I [http:// www.hcfa.gov/coverage/8b3-ff.htm].
85. Krishan G: Isolated Office Hypertension: Ambulatory BP Monitoring Is the Only Answer. Arch Intern Med 2002, 162(13): 1526 .

86. Staessen JA, O'Brien E, Thijs L, Fagard RH: Modern approaches to blood pressure measurement. Occup Environ Med 2000, 57:510-520.

87. Ferrucci L, Furberg CD, Penninx BW: Treatment of isolated systolic hypertension is most effective in older patients with high-risk profile. Circulation 200I, 104:1923-1926.

88. Pocock SJ, McCormack V, Gueyffier F, Boutitie F, Fagard RH, Boissel JP: A score for predicting risk of death from cardiovascular disease in adults with raised blood pressure, based on individual patient data from randomized controlled trials. $B M]$ 200I, 323:75-8I.

89. O'Rourke J, Richardson SW: Evidence based management of hypertension: what to do when blood pressure is difficult to control. BMJ 200I, 322:1229-I 232.

90. Pickering TG: Ambulatory blood pressure monitoring. Curr Hypertens Rep 2000, 2:558-564.

91. Prasad N, Isles C: Ambulatory blood pressure monitoring: a guide for general practitioners. BMJ 1996, 3 I3:1535-154I.

92. O'Brien E, Coats A, Owens P, Petries J, Padfield P, Littler W: Use and interpretation of ambulatory blood pressure monitoring: recommendations of the British Hypertension Society. BM] 2000, 320: I I28-II34.

93. Ramsey L, Williams B, Johnson G, MacGregor GA, Poston L, Potter J: Guidelines for management of hypertension: report of the third working party of the British Hypertension Society. J Hum Hypertens 1999, 13:569-592.

94. Devereux RB, Pickering TG: Relationship between the level, pattern and variability of ambulatory blood pressure and target organ damage in hypertension. J Hypertens Suppl 1991, 9(suppl 8):S34-S38.

95. Giaconi S, Levanti C. Fommei E. Microalbuminuria and casual and ambulatory blood pressure monitoring in normotensives and in patients with borderline and mild essential hypertension. Am J Hypertens 1989, 2:259-261.

96. Shimada K, Kawanato A, Matsubayishi K, Ozawa T: Silent cerebrovascular disease in the elderly: correlation with ambulatory pressure. Hypertension 1990, 16:692-699.

97. Mancia G, Zanchetti A, Agebiti-Rosei E: Ambulatory blood pressure is superior to clinic blood pressure in predicting treatment-induced regression of left-ventricular hypertrophy. Circulation 1997, 95: 1464-1470.

98. Ohkubo T, Imai Y, Tsuji I: Prediction of mortality by ambulatory blood pressure monitoring versus screening blood pressure measurements: a pilot study in Ohasama. J Hypertens 1997. I5:357-364.

99. Staessen JA, Thijs L, Fagard R: Predicting cardiovascular risk using conventional vs ambulatory blood pressure in older patients with systolic hypertension. JAMA 1999, 282:539-546.

100. Perloff $D$, Sokolow $M$, Cowan R: The prognostic value of ambulatory blood pressures. JAMA 1983, 249:2792-2798.

10I. Redon J, Campos C, Narciso ML, Rodicio JL, Pascual JM, Ruilope LM: Prognostic value of ambulatory blood pressure monitoring in refractory hypertension: a prospective study. Hypertension 1998, 3 I:7|2-7|8.

102. Verdecchia P, Porcellati C, Schillaci G: Ambulatory blood pressure, an independent predictor of prognosis in essential hypertension. Hypertension 1994, 24:793-80I.

103. Ernst EE, Bergus GR: Favorable patient acceptance of ambulatory blood pressure monitoring in a primary care setting in the United States: a cross-sectional survey. BMC Family Practice 2003, 4: 15 